\title{
The Occurrence of Diversion Colitis in Patients With a Sigmoid Neovagina
}

\author{
TOON A. M. TOOLENAAR, MD, INGRID FREUNDT, MD, \\ FRANS J. M. HUIKESHOVEN, MD, PHD, AAT C. DROGENDIJK, MD, PHD, \\ HANS JEEKEL, MD, PHD, AND SAVI CHADHA-AJWANI, MD, PHD
}

\begin{abstract}
Diversion colitis is an inflammatory process occurring in segments of the colorectum surgically diverted from the fecal stream. Clinical symptoms of this condition are rectal discomfort, pain, discharge, and bleeding. We diverted isolated segments of sigmoid to create neovaginas in patients with aplasia vaginae and in male to female transsexuals. In contrast to what is reported in most studies of diversion colitis, the neovagina consists of an isolated segment not connected to the anus in patients without any pre-existing bowel disease. To investigate the occurrence of diversion colitis in these sigmoid-neovaginas we studied biopsy specimens from 13 patients. Most of the patients complained of discharge and slight blood loss from their sigmoid-neovagina. Microscopic examination of the biopsy specimens showed lymphocytic infiltration in all cases. Four cases showed an acute inflammatory infiltrate in the lamina propria. Our results indicate that the changes observed on clinical and histopathologic examinations represent the entity of mild diversion colitis. We conclude that diversion colitis also occurs in a sigmoid neovagina. HUM PATHol 24:846-849. Copyright (C) 1993 by W.B. Saunders Company
\end{abstract}

Patients who have a segment of the colorectum surgically diverted from the fecal stream frequently develop a condition known as diversion colitis. ${ }^{1.2}$ Many of these patients become symptomatic with complaints related to the defunctionalized bowel, including rectal discomfort, pain, discharge, and bleeding. Endoscopic features include erythema, friability, edema, ulceration, and obvious bleeding." Histologic abnormalities include aphthous ulceration, crypt distortion, atrophy and abscesses, a villous surface to the colon, and a mixed acute and chronic inflammatory infiltrate with patchy lymphoid hyperplasia. ${ }^{4}$ The incidence of diversion colitis may be as high as $100 \%$ when it is observed prospectively, with the onset between 3 and 36 months after operation. ${ }^{5}$ Patients with diversion colitis initially had loop colostomies or Hartmann's procedure performed for various reasons, including perforated diverticulitis, carcinoma, or trauma.

Encouraged by the results of Kun, ${ }^{6}$ we diverted an isolated sigmoid segment and used it to create a neovagina. ${ }^{7}$ In contrast to what is reported in most studies of diversion colitis, the neovagina consists of an isolated segnent not connected to the anus in patients without

From the Departments of Obstetrics and Gynecology, Surgery, and Pathology, Academic Hospital Rotterdam, Dijkrigt, Rotterdam. The Netherlands. Accepted for publication January 4, 1993.

Key werds: diversion colitis, neovagina, tamssexuality, MayerRokitanskv-Küster syndrome, aplasia vaginae.

Address correspondence and reprint requests 10 Frans J. M. Huikeshoven, MD, PhD, Department of Obstetrics and Gynecology, AZRDijk zigt, Dr Molewaterplein 40, 3015 (iD Rotterdam, The Netherlands.

Copyright ( $\overline{\mathrm{C}}$ ) $1993 \mathrm{by}$ W'.B. Saunders Company

$0046-8177 / 93 / 2408-0005 \$ 5.00 / 0$ any pre-existing bowel disease. To investigate whether diversion colitis also occurs in these patients, we studied the histology of this isolated sigmoid segment.

\section{MATERIALS AND METHODS}

The operative procedure to create a sigmoid neovagina has been described earlier. ${ }^{7}$ Briefly, after dissecting a plane between the bladder and rectum and isolating a sigmoid segment 15 to $20 \mathrm{~cm}$ in length, the oral side of the sigmoid loop is connected with the perineum or the vulva and the aboral side is closed. All patients undergoing operation between 1983 and 1988 were eligible for the study. Twenty-three patients were male to female transsexuals with an obliterated vagina after various procedures. Fourteen patients had aplasia vaginae as a part of the Mayer-Rokitansky-Küster syndrome. Three patients underwent surgery for other reasons.

Thirten patients could not be located. Of the remaining 27 patients, 10 refused to participate in our study for various reasons. Those consenting to participate in this study were given a questionnaire concerning their operation, complaints, and sexual habits.

Speculum examination was done to determine whether erythema, edema, friability, erosions, or stenosis was present. In addition, the luminal content of the neovagina was cultured to detcet the presence of acrobic and anaerobic bacteria. If the patient consented, a biopsy was taken. Biopsy specimens were fixed in buffered formalin, stained with hematoxylin and arophloxin, and serially sectioned. After standard histopathologic examination, the slides were reviewed for histologic features of diversion colitis as described by Komorowski. ${ }^{4}$

\section{RESULTS}

Of the 17 patients examined, four did not consent to a biopsy due to fear of pain. The characteristics of these 17 patients are given in Table 1. None of the patients had a history of gastrointestinal disease. The period between surgery and the follow-up study ranged from 23 to 80 months (mean, 53 months).

Fourteen patients had regular sexual intercourse. The other three had no sexual partner. Fifteen patients used a lubricant. Thirteen patients experienced white sticky discharge from their neovagina. Fifteen patients reported slight blood loss, nine of them spontaneously and six only after sexual intercourse. Three patients complained of cramps in the neovagina, one of them only after intercourse.

Speculum examination revealed erythema in five patients and friability of the sigmoid-neovagina in six patients. Edema, erosions, or stenosis was not found. In most patients the top of the neovagina contained some cellular debris with mucous strands. The clinical 
TABLE 1. Patient Characteristics

\begin{tabular}{|c|c|c|c|}
\hline & $\begin{array}{c}\text { Male to } \\
\text { Female } \\
\text { Transsexuals }\end{array}$ & $\begin{array}{c}\text { Females With } \\
\text { Aplasia } \\
\text { Vaginae }\end{array}$ & All Patients \\
\hline No. of patients & 11 & 6 & 17 \\
\hline \multicolumn{4}{|l|}{ Age } \\
\hline M('an (vi) & 37 & 23 & 32 \\
\hline Range $\left.(y)^{\prime}\right)$ & $20-48$ & $19-28$ & $19-48$ \\
\hline \multicolumn{4}{|l|}{ Follow-up period } \\
\hline Mean (mo) & 50 & 59 & 53 \\
\hline Range (no) & $97-87$ & $23-80$ & $27-87$ \\
\hline No of biopsies performed & 7 & 6 & 13 \\
\hline
\end{tabular}

features are summarized in Table 2 . There was no difference fornd between male to female transsexuals and females with aplasia vaginae.

Microscopic examination of the biopsy specimens showed a spectrum of histopathologic changes, which are summarized in Table 3 . All biopsy specimens showed lymphocytic infiltration in the lamina propria and six biopsy specimens showed fibrosis. Although speculum examination revealed no cases with severe diversion colitis, four cases showed histopathologic signs of a more acute inflammatory infiltrate in the lamina propria, with decreased mucin secretion in one patient and erosions of the surface epithelium in another. Table 3 gives the features of diversion colitis described by Komorowski ${ }^{4}$ and the frequency of occurrence of these features in our patients. Some of these features are shown in Figs 1 and 2. In most of our patients the specimens showed a mild diversion colitis. Results of the bacterial cultures of the luminal content of the neovagina revealed only normal inhabitants of the colon.

\section{DISCUSSION}

To our knowledge the histopathologic changes in a sigmoid-neovagina have not been previously reported in the literature. In 1913 Albrecht reported the first three cases of the successful creation of a neovagina with an isolated sigmoid segment. ${ }^{.}$The method gained acceptance in Eastern Europe, from which Aleksandrov and Gigovski reported 275 and 220 cases of successful operations, respectively, between 1935 and $1968 .{ }^{9}$ In more recent reports Kun, ${ }^{6}$ Pratt, ${ }^{10}$ Dalton, ${ }^{11}$ and Novak et al ${ }^{12}$ reported satisfactory results for patients with congenital aplasia or loss of the vagina after radical cancer surgery and in male to female transsexuals. Most patients have reported routine sexual intercourse. All investigators have reported some discharge from the sigmoid-neovagina.

In 1981 Gilotzer et al were the first to describe the development of inflammation in segments of colon and rectum after diversion of the fecal stream as a specific entity. 'In their series of 10 patients the main features of the disease were described. All patients but one were asymptomatic when the lesion was discovered. The endoscopic findings were similar in appearance to those of mild ulcerative colitis. Microscopic alterations were focal and included crypt abscesses, epithelial cell de-
TABLE 2. Clinical Features in 17 Patients With a Sigmoid-Neovagina

\begin{tabular}{lccc}
\hline & $\begin{array}{c}\text { Male to } \\
\text { Female } \\
\text { Transsexuals } \\
(\mathrm{n}=11)\end{array}$ & $\begin{array}{c}\text { Fenales With } \\
\text { Aplasia } \\
\text { Vaginae } \\
(\mathrm{n}=6)\end{array}$ & $\begin{array}{c}\text { All } \\
\text { Patients } \\
(\mathrm{n}=17)\end{array}$ \\
\hline $\begin{array}{l}\text { Complaints } \\
\text { Discharge }\end{array}$ & & & \\
Blond loss & 8 & 5 & 13 \\
$\quad$ Only after intercourse & 9 & 6 & 15 \\
$\quad$ Spontaneously & 2 & 4 & 6 \\
Ciramps & 2 & 2 & 9 \\
Speculum examination & 2 & 1 & 3 \\
Erythema & 4 & 1 & 5 \\
Edema & 0 & 0 & 0 \\
Friability & 4 & 2 & 6 \\
Stenosis & 0 & 0 & 0 \\
Erosions & 0 & 0 & 0 \\
\hline
\end{tabular}

generation, acute and chronic inflammation in lamina propria, and degenerative changes in the crypts. When bowel continuity was restored the condition subsided. Recently, Geraghty and Talbot described the histopathologic features of diversion colitis in resected specimens of defunctioned large bowel from 15 patients. ${ }^{13}$ Their findings comprised diffuse mild chronic inflammation with or without mild crypt architectural abnormalities, crypt abscesses, or follicular lymphoid hyperplasia. The incidence of diversion colitis may be as high as $100 \%$ when it is observed prospectively, with the onset occurring between 3 and 36 months after operation. ${ }^{5}$

The pathologic features described by Geraghty and Talbot ${ }^{13}$ are fairly similar to those found in our patients. Therefore, we believe that our results indicate that the

TABLE 3. Histologic Features in 13 Patients With a Sigmoid-Neovagina

\begin{tabular}{|c|c|c|c|}
\hline & $\begin{array}{c}\text { Male to } \\
\text { Female } \\
\text { Transsexuals } \\
(\mathrm{n}=7)\end{array}$ & $\begin{array}{l}\text { Females } \\
\text { With } \\
\text { Aplasia } \\
\text { Vaginae } \\
(n=6)\end{array}$ & $\begin{array}{c}\text { All } \\
\text { Patients } \\
(n=13)\end{array}$ \\
\hline \multicolumn{4}{|l|}{ Surface epithelium } \\
\hline Absence of mucous layer & 2 & $\underline{9}$ & 4 \\
\hline Decreased mucin secretion & 0 & 1 & 1 \\
\hline Erosions & 1 & 0 & 1 \\
\hline Villous surface & 0 & 0 & 0 \\
\hline \multicolumn{4}{|l|}{ Crypts } \\
\hline Distortion & 4 & 3 & 7 \\
\hline Bifid form & 1 & 0 & 1 \\
\hline Cystic dilatation & 1 & 0 & 1 \\
\hline Atrophy & 2 & 2 & 4 \\
\hline Abscesses & 0 & 0 & 0 \\
\hline Paneth cell metaplasia & 2 & 2 & 4 \\
\hline \multicolumn{4}{|l|}{ Lamina propria } \\
\hline Edema & 9 & 0 & 2 \\
\hline Fibrosis & 3 & 3 & 6 \\
\hline Ixmphocytic infiltrate & 7 & 6 & 13 \\
\hline Veutrophilic infiltrate & 2 & 2 & 4 \\
\hline Mucin granuloma & 0 & 0 & 0 \\
\hline Lymphoid follicles & 2 & 2 & 4 \\
\hline
\end{tabular}

Note: The criteria used are those of Komorowski. ${ }^{4}$ 


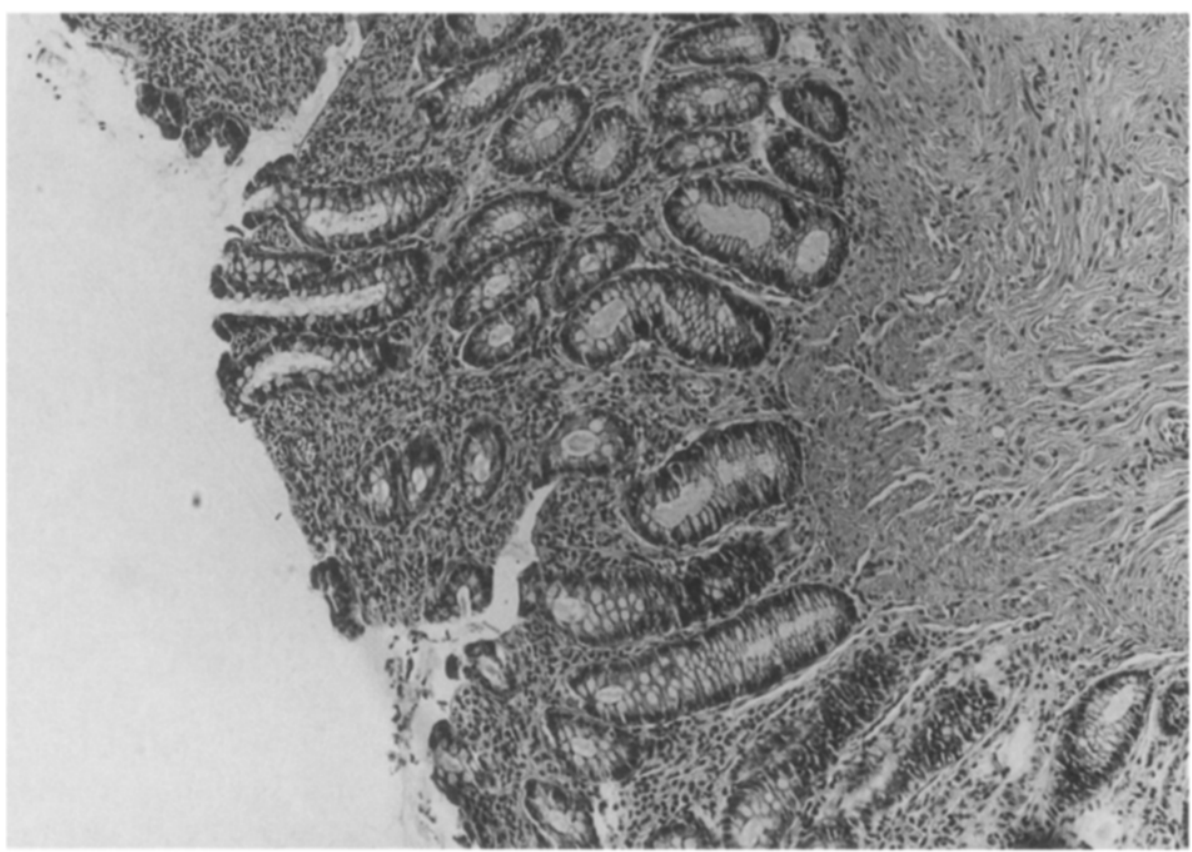

FIGURE 1. Biopsy specimen showing crypt distortion.

changes observed on clinical and histopathologic examinations are caused by a diversion colitis leading to the discharge reported in our patients as well as those included in other series. To our knowledge, we are the first to describe the occurrence of this condition in patients with a sigmoid-neovagina. Our patients, healthy women with the Mayer-Rokitansky-Küster syndrome or male to female transsexuals, differ from patients in other published series due to the fact that the isolated signoid segment is used as a vagina in which regular intercourse takes place. All our patients had minor complaints, such as slight blood loss or discharge from their neovagina, and the diversion colitis we found in our material was mild.
Various unproven etiologies have been proposed for diversion colitis." These include the effect of stasis, bacterial overgrowth in the bypassed segment, and the invasion by pathogenic organisms. In our series we cultured only normal inhabitants of the colon. This is in agreement with the finding of Neut et al in their study of bacterial flora of human excluded colon. ${ }^{14}$ The deprivation of essential nutrients (specifically, short chain falty acids) is another proposed etiology. Short chain fatty acids are the predominant solutes in the aqueous phase of colonic contents and stool. These acids are produced by the anaerobic fermentation of carbohydrates. Roediger demonstrated that short chain fatty acids are the preferred energy source for human colonic

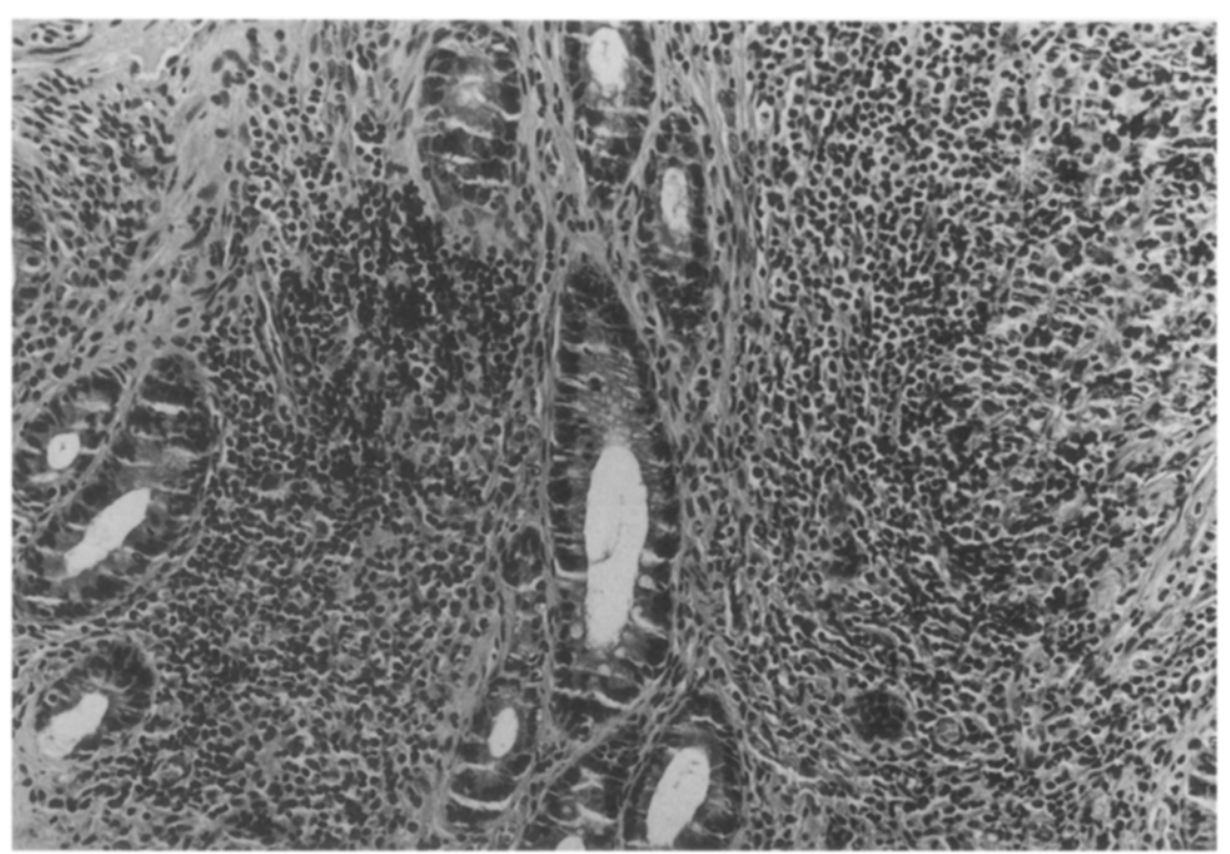

FIGURE 2. Biopsy specimen showing lymphoid hyperplasia. 
epithelium. ${ }^{15}$ Evidence to support a nutritional deficiency as the etiology of diversion colitis has been offered by Harig et $a{ }^{16}{ }^{16}$ who found the absence of any notable bacterial fermentation-producing short chain fatty acids in patients with diversion colitis. These investigators reported marked improvement in the endoscopic and histologic alterations in the diverted segment after short chain fatty acids were supplied to the colon by local application. Because our study was performed after a long follow-up period (mean, 53 months), we expected to find cases with macroscopic signs of an active inflammation. All our patients who have routine sexual intercourse use lubricants of which methylcellulose or carboxymethylcellulose is the main ingredient. Although we did not measure the amount of short chain fatty acids in the sigmoid-neovagina, they may be produced in sufficient amounts by the fermentation of methylcellulose by anaerobic bacteria to prevent a full-blown diversion colitis.

\section{REFERENCES}

1. Ciloter I)], Cilick ME, Goldman H: Prowtitis and colitis following diversion of the fecal stream. Gastroenterology $80: 438-441$. 1981

2. Ma C:K, Gottlieb Ci, Haas PA: Diversion colitis: A clinicopathologic study of 21 cases. Hum PATHOI, 21:429-436, 1990)

3. Agarwal VP, Schimmel EM: Diversion colitis: A nutritional deficiency syndrome: Nut1 Rev 47:257-261, 1989
4. Komorowski RA: Histologic spectrum of diversion colitis. Am I Surg Pathol 14:548-554, 1990

5. Korelitz BI, I awrence JC, Sohn N, et al: The fate of the rectal segment after diversion of the fecal stream in Crohn's disease: Its implications for surgical management. J Clin Gastroenterol 7:37-45, 1985

6. Kun M: Colpopoiesis From the Colonn. Budapest, Hungary, Akademiai Kiado, 1975

7. Freund 1, Toolenaar $\triangle A M$, Huikeshoven FJM, et al: A modified technique to create a neovagina with an isolated segment of sigmoid colon: an evaluation of 40 cases. Surg Gvnecol Obstet 174:1 116,1992

8. Albrecht P: Cber plastischen Ersacz der Vagina bei Angeborenem Defect derselben. Disch Z Chir $122: 562-590,1913$

9. Kinderman (;: Die Sigmascheide: Erfahrungen in der Behandlung bei angeborencr Fehlen oder spateren verlust der vagina. Creburtshilfe Fratuenheilkd 47:650-65.4, 1987

10. Prat $\mathrm{JH}$ : Vaginal atresia corrected by use of small and large bowel. Clin Obstet Gynecol 15:639-649, 1972

11. Dalton JR: Use of sigmoid colon in sex reassignment operations. Lrology 17:223-227, 1981

12. Nowak F, Kos L., Pleško F: The advantages of the artificial ragina derived from sigmoid colon. Acta Obstet Gynecol Scand 57: $95-96,1978$

13. Geraghty IM. Tabot IC: Diversion colitis: Histological features in the colon and rectum after defunctioning colostomy. Gut 32: $1020-1023,1991$

14. Veut (: Colombel JF, Guillemot E, et al: Impaired bacterial flora in human excluded colon. Gut 30:1094-1098, 1989

15. Roediger WE: Role of anaerobic bacteria in the metabolic welfare of the cotonic mucosa in man. Gut $21: 793-798,1980$

16. Harig JM, Sorergei KH, Komorowski RA, et al: Treatment of diversion colitis with short-chain-fatty acid irrigation. N Engl J Med $320: 23-28.1989$ 